\title{
Public Access to Environmental Information: Past, Present and Future
}

\author{
Mordechai E. Haklay \\ D epartment of G eomatic Engineering and the Centre for Advanced Spatial Analysis \\ University College London \\ G ower Street \\ London WC1E 6BT \\ e-mail:m.haklay@ucl.ac.uk \\ Tel: (+44)-20-7679-4725 \\ Fax: (+44)-20-7380 0453
}


Forthcoming in "Computers, Environment and Urban Systems"

\section{Abstract}

Since the late 1960s and the "environmental revolution", information and information systems have been an integral part of the environmental debate. In the decade that has passed since the Rio conference and the establishment of the "sustainable development" principle, there have been legislative and practical moves to open access to environmental information for all stakeholders that are involved in environmental decision making processes. In this paper, the origins of environmental information and public environmental information systems are explored and scrutinised. The paper questions the current state of the art in environmental information provision, and offers some directions for possible improvements.

\section{Keywords}

Environmental information, Environmental Information Systems, public access, environmental GIS. 
Forthcoming in "Computers, Environment and Urban Systems"

\section{Introduction}

From the outset of the modern environmental movement, information and information systems have played an intriguing part. As environmental issues secured their position on national and international agendas, environmental information followed suit. The development of computersupported environmental models and environmental information systems has happened in continuously changing social, political and economic environments. O ne of the recent and profound changes in this area occurred during the 1990s, with the growing acceptance of the principle of wide public access to environmental information. For example, the "Convention on Access to Information, Public Participation in Decision Making and Access to Justice in Environmental Matters" - the Aarhus Convention - which was signed by the members of the United Nations Economic Commission for Europe (UN/ ECE) promoted access as a means to improve public participation in environmental decision making and awareness of environmental issues (UN/ ECE, 1998) (this convention is expected to come into force by the end of 2001). As we approach the 2002 Earth Summit (Rio+10), the time is ripe to evaluate this issue and its future directions. The vast literature that covers computer use for environmental application - spanning modelling, monitoring, management and so on - seems to pay little or no attention to the needs and requirements of different user groups and audiences. Yet, current demands for wide spread access to environmental information would imply a more central role on the research agenda. The aim of this paper is to provide a general introduction to this research topic and to present some of the questions that relate to it.

The paper opens with a conceptual framework that tries to capture the current state of the art in public access to environmental information. The framework is based on six assertions (A-F), gleaned from an examination of the literature and the history of environmental information and public 
Forthcoming in "Computers, Environment and Urban Systems"

access to it. The second section of the paper focuses on the history of environmental information, and aimed to establish foundations for the framework. In the third section, the framework is reexamined and used as a basis for the development of a research agenda. The fourth section uses this agenda to examine current practice in information provision. Directions for future research are offered in the final section.

\section{Explaining Public Environmental Information Systems}

As the following review will demonstrate, most of environmental information is stored in computerised information systems, and G eographical Information Systems (GIS) are a major technology that is widely used in Environmental Information Systems (EIS). In accordance with the growing demand for public access to this information, there is a growing need for publicly accessible Environmental Information Systems (PEIS). Review of current EIS and PEIS (Haklay, 2001) reveals a set of six assertions that seem to underlie current practice:

A. Sound knowledge, reliable information and accurate data are vital for good environmental decision making.

B. Within the framework of sustainable development, all stakeholders should take part in the decision making processes. A direct result of this is a call for improved public participation in environmental decision making.

C. Environmental information is exceptionally well suited to G IS (and vice versa). G IS development is closely related to developments in environmental research, and GIS output is considered to be highly advantageous in understanding and interpreting environmental data.

D. (Based on A and B) To achieve public participation in environmental decision making, the public must gain access to environmental information, data and knowledge. 
E. (Based on A and C) G IS use and output is essential for good environmental decision making.

F. (Based on all the others) Public Environmental Information Systems should be based on GIS technologies. Such systems are vital for public participation in environmental decision making.

Figure 1 presents the relationship between the assertions.

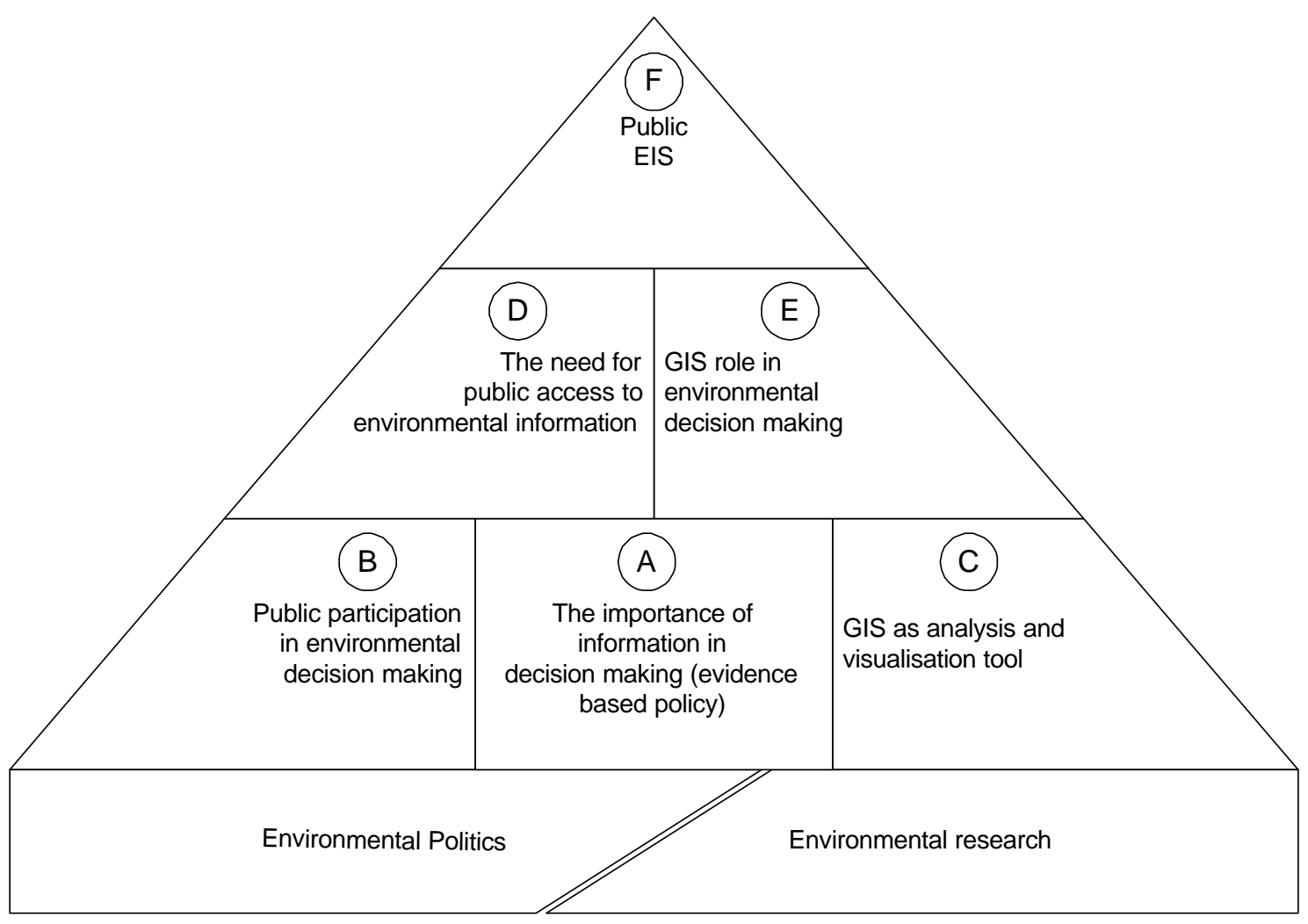

It is important that each of these, and especially the first three, basic, assertions, be viewed within a wider social and institutional context. Assertion A relates to a growing demand for accountability from public institutions and calls for evidence and criteria-based decision making. Assertion B should be considered within the wider framework of participation in decision making, which 
Forthcoming in "Computers, Environment and Urban Systems"

predates sustainable development and goes beyond strictly environmental topics ${ }^{1}$. However, within the framework of "sustainable development" and the influential Bruntland report (WCED \& Brundtland, 1987), the concept of public participation was elevated into a special position that sometimes seems to see it as an end in and of itself. As for assertion C, it is important to note that within the practice of environmental information production by environmental scientists and professionals, GIS is not used in isolation. However, as we shall see, GIS is an overwhelmingly dominant technology within environmental information systems. The importance of the assertion framework lies in its attempt to generalise and describe the major elements of ament practice within PEIS.

In the following section, the six assertions will be substantiated through an examination of the history of environmental information. This historical overview uses major events and documents in the "environmental movement timeline", to demonstrates the role of environmental information within them. Although the review relies mainly on the UN system and the international level, similar trends can be explored at the national level.

\section{A Brief History of Environmental Information}

\section{The Early Years}

In most accounts, the publication of Rachel Carson's "Silent Spring" (Carson, 1962) is considered as a turning point for the $20^{\text {th }}$ century environmental movement and the emergence of "the

1 For examples of comprehensive analysis in the field of planning see the widely cited "collaborative planning" (Healey, 1997), and for reviews of the current situation within the UK, where participation is considered central to the government's agenda, see Lowndes, Pratchett \& Stoker (2001a; 2001b) and Wilson (1999). 
Forthcoming in "Computers, Environment and Urban Systems"

environment" as a substantial topic on the public agenda (Liverman, 1999; Lowenthal, 1990;

McCormick, 1995). Y et, environmental awareness was not invented in the 1960s, and what we today might call environmental politics predates this era (Lowenthal, 1990). However, the 1960s serve as a clearly-defined turning point and the era of the "environmental revolution" (McCormick, 1995). The connection between regulatory measures and the collection of information dates to the early responses to the modem environmental movement. One of these milestones is the USA National Environment Policy Act - NEPA (1969). NEPA explicitly binds environmental politics and information. The two main implementation vehicles established in it are an annual report on the state of the environment and environmental impact assessment (EIA); both can be interpreted as information tools. NEPA also make the connection between environmental information and any interested party. When EIA is described, it states:

"All agencies of the federal government shall ...

(G) make available to States, counties, municipalities, institutions, and individuals, advice and information useful in restoring, maintaining, and enhancing the quality of the environment;

(H) initiate and utilise ecological information in the planning and development of resource-oriented projects; "(U.S. Congress, 1970, Sec. 102)

NEPA goes on and connects information utilisation, in the "job specification" for the Council for Environmental Quality (CEQ) members:

"... Each member shall be a person who, as a result of his training, experience, and attainments, is exceptionally well qualified to analyse and interpret environmental trends and information of all kinds... "(U.S. Congress, 1970, Sec. 201) 
Forthcoming in "Computers, Environment and Urban Systems"

In short, though NEPA sets out to deal with national policy to "encourage productive and enjoyable harmony between man and his environment" (U.S. Congress, 1970), it implements it through the production and use of information.

The United States were not the sole active scene of political change. Other countries went through similar shifts in policy and public awareness in this period. For example, the UK went thorough several changes during the late 1960s. The creation of the Royal Commission on Environmental Pollution (1969) and the Department of the Environment (1970) are the governmental response to public pressures (McCormick, 1995). It is now commonly accepted that this period marks the awakening of environmental awareness throughout the developed world (Hajer, 1995; McCormick, 1995). The major global event that marks this period is the United Nations conference on "The Human Environment" held in Stockholm in June 1972. In the action plan of the conference, information (and the exchange of information) is mentioned over 60 times (UN, 1972). The major outcome from the conference was the creation of the United Nation Environmental Programme (UNEP). From its inauguration, UNEP saw the collection of data and information about the environment as its most urgent task (Wallen, 1997), based on the "Earthwatch" principles - the evaluation and review of existing knowledge; creation of new knowledge through research; information gathering through monitoring activities and information exchange (UN, 1972, Sec. C). Once the programme started, considerable gaps in data and knowledge have been found, and the task to fill them was handed to the Global Environment Monitoring System (GEMS) unit. By the end of the 1970s, GEMS had created INFOTTERA - the International Environmental Information System - probably the first of its kind (Wallen, 1997). INFOTTERA was operated through national focal points and provided the service of locating sources of environmental information through computerised queries (UNEP, 1979). 
Forthcoming in "Computers, Environment and Urban Systems"

O ther notable activities on the international scene happened in Europe. In 1973, the European Community (EC) moved, for the first time, beyond strictly economic issues to establish the EC environmental programme (Briggs, 1986) - a medium term plan with declared targets and goals. Though the first programme did not target informational issues directly, by the second action plan (amended in June 1977) environmental information took centre stage, alongside EIA. Some of the directives and regulations that stem from those policies relate directly to data collection and information. For example, in 1979 the EC established a programme for the exchange of information on atmospheric pollution, focusing on data collection methods and improved comprehensiveness and compatibility of such data (Briggs, 1986).

\section{Environmental Information and Sustainable Development}

Although informational activities continued to evolve in the period that followed ${ }^{2}$, for this review it is appropriate to move on to the developments of the late 1980s, and the publication of "O ur Common Future" (WCED \& Brundtland, 1987) and the subsequent UN activities. These culminated with the conference on "Environment and D evelopment" held in Rio de Janeiro, June 1992. The Rio declaration and Agenda 21 link public access to information to the principle of sustainable development. Principle 10 of the declaration reads:

"Environmental issues are best handled with the participation of all concerned citizens, at the relevant level. At the national level, each individual shall have appropriate access to information concerning the environment that is held by public authorities, ...

\footnotetext{
${ }^{2}$ One such information-oriented activity is the recommendations in the subsequent document to "Global 2000 Report to the President" titled "Global Future: Time to Act" that called for reorganisation of the United States government and the creation of a new centre for co-ordination of data-gathering and modelling to support policy formulation (McCormick, 1995).
} 
Forthcoming in "Computers, Environment and Urban Systems"

and the opportunity to participate in decision-making processes. States shall facilitate and encourage public awareness and participation by making information widely available... " (UN, 1992b, Principle 10).

The declaration mentions environmental information in other places (EIA at the national level is mentioned in principle 17 and information sharing about transboundary impacts in Principle 19). Agenda 21 pays special attention to information: in each chapter, a section is dedicated to data collection and information. Moreover, Chapter 40 of the agenda is dedicated to "information and decision making" and states:

"In sustainable development, everyone is a user and provider of information considered in the broad sense. That includes data, information, appropriately packaged experience and knowledge. The need for information arises at all levels, from that of senior decision makers at the national and international levels to the grass-roots and individual levels. ... " (UN, 1992a)

Two aspects of this focus on environmental information are noteworthy. Firstly, the Agenda emphasises the role of special kinds of information systems. These are G IS and remote sensing systems (mentioned in connection with human settlements, deforestation, agricultural and rural development, ocean protection, and fresh water). This is of particular interest, especially when compared with the general reference to "information technologies" or "state-of-the-art data management technologies" that appears in other parts (Chapter 8, for example). Though other types of information systems are mentioned here and there (such as expert system), G IS appears time and again in many chapters (but is not mentioned when land resources are discussed!).

Secondly, special attention is paid to public access to environmental information. Both the declaration and Agenda 21 mention it (as the earlier citations demonstrate). Section III of the 
Forthcoming in "Computers, Environment and Urban Systems"

Agenda, dedicated to "Strengthening the Role of Major G roups" connects the need to integrate women, children and youth, indigenous people, Non G overnmental O rganisations (NG Os), local authorities, trade unions, business and industry, science and technology, and farmers with access to information. The preamble to this section declares:

"... Individuals, groups and organisations should have access to information relevant to environment and development held by national authorities, including information on products and activities that have or are likely to have a significant impact on the environment, and information on environmental protection measures... " (UN, 1992a, Chapter 23, sec 23.2)

Current developments in environmental politics are frequently related to Agenda 21 and to the principle of Sustainable D evelopment, in what seems to support the framework of "ecological modernisation" ${ }^{13}$ (Blowers, 1997). As Blowers (1997) noted, Sustainable development is "at once a scientific principle, a political goal, a social practice and a moral guideline" (p. 846).

In the context of ecological modemisation, public access to environmental information should be seen as part of a more general principle of public participation in environmental decision making. However, several developments during the 1990s target this issue specifically. On the legal side, conventions that promulgate public access to environmental information have been developed and signed. These include the European Council Directive 90/ 313/ EEC, "Freedom of Access to Information on the Environment" and the Aarhus convention (UN/ ECE, 1998). In the latter, the following statements can be found:

${ }^{3}$ See Hajer (1995) for broader discussion (and critique) of ecological modemisation. 
Forthcoming in "Computers, Environment and Urban Systems"

"Improved access to information and public participation in decision-making enhance the quality and the implementation of decisions, contribute to public awareness of environmental issues, give the public opportunity to express its concerns and enable public authorities to take due account of such concerns" (p. 2)

Other developments include the creation of purpose built information systems to serve environmental information to the public. These systems will be in the centre of attention in the following sections.

\section{Opening access to environmental information}

Environmental politics and environmental discourse have gone through a profound change between the first era (1960s to early 1970s) and the current period. The narrow scientific view of environmental management and control is deeply embedded in "Silent Spring", NEPA, the US Clean Air Act, early UNEP programmes and other regulations surrounding environmental issues. This is not the case with "O ur Common Future" and the subsequent "ecological modernisation". In this era, environmental concepts became embedded into all human activities. It is no more the secluded responsibility of an obscured public agency. This time, at least in principle, the focus is on an inclusionary form of decision making. So much so, that "O ur Common Future" urges us to take into consideration the needs of non-humans and those of the future generations (Wced \& Brundtland, 1987). This principle has implications on environmental information. As has been shown, environmental information and data have been always perceived as imperative for environmental decision making. Therefore, it must be exposed and shared with all those concerned in formulating and implementing the decision. 
Forthcoming in "Computers, Environment and Urban Systems"

Since the environmental revolution of the 1960s, and the 13 years that have passed since 1987 and the publication of "O ur Common Future", environmental problems seem to have held their position in the political agenda (McCormick, 1995). The signs of current public awareness are everywhere. Using current signs as indicators for the future, we can speculate that it is likely that we will have to deal with environmental politics well into the $21^{\text {st }}$ century. This will include facing the challenge of providing better public access to environmental information.

\section{Questioning public access to environmental information}

The review of environmental information history provides the foundations for the assertion framework (Figure 1). Although it seems that these assertions have a logical flow, they represent several conceptual leaps that must be scrutinised. The three basic assertions (A, B \& C above) stem from different "segments" of the environmental arena. The first comes from an institutionalised response to the environmental movement, the second is based on grass-roots pressure and the third emerges from scientific-technical circles. Assertion D is arguably the basis for grass-roots pressure for access to environmental information and the reason for environmental NG Os to champion "Freedom of Information" issues. Assertion E can explain the integration of G IS into major environmental conventions (such as Agenda 21) and systems (such as UNEP), and finally, F explains observations on existing PEIS. F is also important for a certain research theme in G eography Public Participation GIS (PPG IS). This theme emerged in the second half of the 1990s and has attracted attention from many sub-disciplines in current day G eography ${ }^{4}$. Notably, the connection

4 See the newly published "Community Participation and GIS" (Craig \& al., forthcoming) for a comprehensive overview of this field. 
Forthcoming in "Computers, Environment and Urban Systems"

between public participation (B) and GIS (C) is the outcome of a move toward information-based decision-making and evidence-based policy.

What is the basis for the logical flow? How stable are the foundations of each assertion?

The first three assertions are well established. As shown in the previous section, they appear in the texts of international conventions and general literature. Though they can be questioned, there is enough supporting evidence to accept them. Moreover, they are all part of the way environmental politics are conceptualised and framed. This is apparent in the acceptance of GIS by environmental NG Os (Pipes \& Maguire, 1997; Sieber, 1998), or in the involvement of NG Os in the discussions leading to the Aarhus convention (OECD , 2000) and Rio. Therefore, for our discussion they will be accepted in an "axiomatic" manner.

The derived assumptions (D-F) are more problematic. Unquestionably, access to environmental information plays a major role in public disputes, e.g., the first litigation that used the (then new) requirements for an EIA, held during the first months of 1970. In this case (an oil-pipe line in Alaska), the information that was gathered for the EIA was challenged in court and the demand for access this information came from environmental activists (Mowrey \& Redmond, 1993). D oes it mean that aryenvironmental information is useful to the public? What view of "public" should we accept: the public as a monolithic entity or as a set of single-issue interest groups or other forms? What kind of information should we declare as "environmental"?

Any overview of environmental politics (such as Hajer, 1995; McCormick, 1995) reveals changes in framing, focus, topics and awareness to environmental issues throughout the years. How should public access to environmental information reflect those changes? Finally, what is the relationship 
Forthcoming in "Computers, Environment and Urban Systems"

between public participation and public access to information? Are they inseparable or should we analyse access to information separately?

The foundations of the next assertion (E) are more secure. The growth of the use of GIS in the last decade must be attributed, at least partially to its use as a decision-support tool. This use stems from many studies that treat GIS as such, and the term Spatial D ecision Support System or SD SS was coined for it (D ensham, 1991). These studies are based on real problems to which G IS technology provides useful solutions. Any major book about GIS can attest to this (Longley, Goodchild , Maguire \& Rhind, 1999; Maguire, G oodchild \& Rhind, 1991). This is true for environmental applications, too (see G oodchild, Parks \& Steyaert, 1993;G oodchild, Steyaert, Parks, Johnston, Maidment, Crane $\notin$ al., 1996). How vital is the use of GIS for good environmental decision making? As mentioned earlier, EIA represents a widely used environmental decision support tool. In a survey by João and Fonseca (João, 1998; João \& Fonseca, 1996), it was demonstrated that even though many practitioners know about GIS, it was not used in many cases (due to cost, expertise and other factors). Can we claim that the EIA and the corresponding decision are of a lower quality?

Further more, as many environmental NG O s use GIS intemally for their own goals (Sieber, 2000), and as these NG O s become more professional and gain more credibility (Porritt, 2000), the issue of different versions of data bases, models, analysis and visualisation becomes more acute. Is the use of GIS becomes the "entry ticket" for credibility in environmental decision making? Here Sieber's $(1998 ; 2000)$ work deserves attention. What is the impact of GIS use on decision making processes within NGO s? And within corporations?

The value of GIS in environmental decision making is an open question. Examination of existing literature will reveal a lack of knowledge about how much G IS use contributes to the final decision. 
Forthcoming in "Computers, Environment and Urban Systems"

These basic problems with assertions D and $\mathrm{E}$ shake the foundations of the last assertion and force us to question it. In what follows, I aim to deal with them, and especially to explore aspects of the final assertion about PEIS. The main aim therefore, is to develop a better understanding of the audiences of PEIS, the information that such systems should hold and the appropriate delivery mechanisms.

Such analysis of PEIS at a conceptual level touches on an interesting aspect of environmental information research. When considering the overwhelming embedding of information into the environmental discourse, we would expect to find analysis and evaluation of information in general, and information systems in particular. Parallel fields (such as the study of information systems in general, or G IS) have developed extensive literature in both academic forms (journals and books) and more popular forms, targeted to professionals who work in the area (trade magazines and howto books). Surprisingly, this is not the case with Environmental Information Systems and very limited amount of literature deals with EIS directly (such as Avouris \& Page, 1995; Gunter, 1998). Most of it focuses on implementation issues, especially when compared to the extensive body of research that exists on environmental modelling and analysis techniques. There seems to be a major lack of research on usefulness, requirements and broader analysis which, in contrast, is common in Information Systems research.

\section{Public perspectives on environmental information and current practice}

In order to gain a better knowledge of public perspectives on environmental information, a purposely-designed study was carried out. The study adopted a bottom-up approach, i.e. that PEIS should be based on the requirements and needs of the public. These requirements were gauged through empirical studies: the London Environment O nline (LEO) user survey (Haklay, 2000) and the UCL Brownfield research network (UBRN) workshop (Aurigi, Batty, Bloomfield, Boott, Clark, 
Forthcoming in "Computers, Environment and Urban Systems"

Haklay \&al., 1999). The LEO survey was designed and administered to reveal attitudes, requirements and needs from a proposed urban PEIS (in this case, for London). It was implemented through a World Wide Web (WWW) interface, and respondents were recruited through the use of email and leaflets. The UBRN workshop gave an opportunity for a qualitative and detailed examination of interaction with environmental information, mediated through GIS. This was done during a workshop, in which dozen representatives of local pressure groups explored issues surrounding Brownfield development. The workshop included hands-on experience with GIS and a follow up focus-group discussion.

The analysis of the study results demonstrated that the view of the public as a monolithic body (which many existing public EIS implicitly manifest) is inadequate and should be replaced with realisation of multiple audience perspectives. Users of environmental information do not align themselves with a single perspective, but have "multiple identities" which are used accordingly in different contexts and mindsets. For example, a researcher that is interested in air pollution levels for her daily work, may be interested in local planning applications and their impact when she is at home. Although this statement might seem trivial, examination of existing public EIS show that this multiplicity is not reflected in the design of these systems. Most systems provide a single contact point or interface through which access can be carried out, and do not provide customised access to various audiences. For example, the US Environment Protection Agency (EPA) web site (http:/ / www.epa.gov/ ), which stands out as an example for Public EIS that provides specialised sections for some audience groups, does not implement this division throughout the system. The information architecture of the site conveys the message that the sections targeted at specific audiences are separate from the main system, and contain information that is of specific interest to this audience. The majority of the system does not differentiate between groups and assumes that one size fits all. The UK air quality archive (http:/ / www.aeat.co.uk/ netcen/ airqual/ welcome.html) 
Forthcoming in "Computers, Environment and Urban Systems"

serves as an example of a system that provides multiple entry points to similar information, while appreciating the various needs of different interest groups.

A second valuable finding from the analysis is that in many contexts these audiences view environmental information in a holistic way. As many have noted, environmental politics integrate multiple contrasting views, which usually transcend disciplinary boundaries (Hajer, 1995; Benedick, 1991; Latour, 1993) - for example, the ozone problem is not just a problem of reaction between molecules in the stratosphere, rather it connects issues relating humans, economics, agriculture, manufacturing and developing countries. It is therefore not surprising to discover that environmental information is seen as part of a whole and users expect to see a cumulative picture of the environment. The elements from which this picture will be constructed are different and relate to the specific position of the individual user. Therefore, a keen cyclist would like to see public cycle paths integrated into PEIS, whereas an activist who approaches environmental issues with a strong social conviction would like to see deprivation indices as part of it. Furthermore, many users are interested in environmental information as part of their general information consumption (in a similar way to news consumption through "old" media). Therefore, there is a need to present environmental information in ways that are adequate to such a viewpoint - the information should relate to current concerns or for current topical issues and provide a rich information that will support such needs.

D ue to their developmental history, existing EIS tend to present environmental information in thematic and issue-based ways. Air pollution information is presented in isolation from other information, chemical releases in an inventory way and so on. When considering the organisational structure within which these systems operate, it is understandable that such divisions evolve. As a result, most existing public EIS do not accommodate the need to integrate multiple data sets and contrast them. 
Forthcoming in "Computers, Environment and Urban Systems"

Thirdly, in the light of the holistic view of environmental information, it should not be surprising that maps and GIS are perceived as essential components of public EIS. The participants of the two studies expressed their interest in map-based visualisation of environmental information. In the same way that other studies have noted (Fedra, 1993; João, 1998), G IS the capability of integrating various datasets and visualising their juxtaposition. Moreover, it was demonstrated that basic concepts of spatial analysis (such as overlay) seem natural even to novice users of such systems, once exposed to them. The interesting aspect that came out from the workshop, is the use of GIS in an exploratory way, in which the participants use the tool to explore various aspect of the situation and to evaluate how various environmental components influence and interact with it. This is akin MacEachren's geographical visualisation principles (MacEachren, 1995)

Fourthly, the studies demonstrated the public interest in processed information, for example the output of environmental models (such as flood plain models). There was far less interest in access to "raw data" than in interpreted information. These findings concur with those of the user requirement study of the EPA (Princeton Economic Research Inc., 1998) in which various user groups have expressed interest in interpreted information. The interest of an asthmatic user is not in the current level of ozone at ground level, but an answer to the question "am I going to suffer an attack today", which requires some processing of the previous piece of information. Interestingly, in spite of current claims of distrust in science, it seems that for many aspects of environmental politics, the outputs of models are more significant than access to raw or unprocessed data. This aspect make the issue of properly documented information and the use of metadata especially important (Chrisman, 1994).

Finally, and not surprisingly, when considering the studies population there was a notion that the Internet is a good and adequate medium for information delivery. However, this aspect was not accepted uncritically, and environmental issues were connected to social equity ones. Participants 
Forthcoming in "Computers, Environment and Urban Systems"

have voiced their concern about the exclusiveness of this medium. These concerns have been studied empirically in what is now known as the "Digital Divide" (USD OC/ NTIA, 1995;1998;1999). This is an important aspect, which the tendency to use professional jargon in existing EIS making more acute. In some cases, system designers are using jargon from several fields in one system, and the use of GIS to underlie such systems just makes the situation more complex. D ue to its multiple origins (cartography, databases, computational geometry and so on), GIS is notoriously saturated with specialised terms (Traynor \& Marian, 1995) and these terms "pop up" in PEIS. This aspect adds to the obstacles that make PEIS less accessible and usable. Therefore, EIS designers and maintainers should take care when they claim that public outreach can be achieved by providing an Internet access to the information. This access should be a part of a wider outreach strategy which deals with the societal aspects of information and communication technologies (ICT).

\section{Improving Public Environmental Information Systems}

As the above analysis has demonstrated, there is a considerable gap between the conceptual framework that a would-be user of environmental information can hold and the current state-of-theart in environmental provision. This gap is of special concern, as was shown in the studies that have been conducted and those that have been reviewed. In these studies, the participants were drawn from groups that already expressed interest in environmental issues. As the introduction vividly demonstrated, the principle of access to environmental information is directly connected to the goal of improved public awareness to environmental issues and improved participation in environmental decision making. Therefore, the failure to furnish the needs of those who are already aware force us to question the likelihood of achieving the wider aim of improving public awareness. By realising that the issue of public access to environmental information should not be examined from 
Forthcoming in "Computers, Environment and Urban Systems"

infocentric perspectives but from a rich one that takes into account the social and political context, some remedies can be offered.

First and foremost, PEIS are inherently different from EIS, as the latter have been designed and built for professional use. In many cases, the public interface is being conceived in the same way in which professional documents are published, without customisation. PEIS need special attention from inception to maintenance. They need to be designed specifically for (non-trivial) user groups, and to take into account the multiplicity of needs and views.

Secondly, while a common worldview can be assumed when EIS are being constructed in professional settings, such an assumption cannot be made about PEIS. In professional settings, and when information is shared among environmental professionals, it can be assumed that they share a scientific worldview (in its broadest sense) and know how to evaluate the quality of the information and how to assess it. That is, despite disciplinary differences, organisations such as the UK Environment Agency or the US EPA seem to be capable to develop an organisation-wide EIS. However, once the information is released into the public domain, this assumption cannot stand and must be replaced with an opposite view. In other words, in PEIS the starting point is that a shared worldview does not exist and cannot be assumed. The conceptual framework of each user is unique and relates to the task that she is trying to achieve by using the system - it might be checking the environmental quality of a new place to which she might consider moving, or just browsing as a result of passing interest. Furthermore, her level of knowledge and belief in scientific information is not known. An inadequate approach - either through "dumbing down" the system, or using vocabulary and terminology that is too sophisticated - will alienate users. As is true with other 
Forthcoming in "Computers, Environment and Urban Systems"

information resources, it is a mistake to choose a mediocre solution that satisfy no one (Raskin, 2000).

The different levels of expertise need background knowledge and social environments should force EIS designers to the conclusion that the "one size fits all" rule cannot be applied to PEIS. There is a need to develop systems for the experts, another system for the decision-makers and yet another for the wider public. However, computers are flexible enough that the technology can support the provision of different views to different users. Of course, different views should share underling data sources. On the technical front, technologies such as intelligent agents, collaborative filtering and other advances can help in the development of appropriate PEIS.

Though the aspects that have been reviewed pose a formidable challenge to PEIS designers, current knowledge in various fields can be deployed and used to inform their development. The areas in question are: development of different views for different users, the use of a bottom-up approach to public access, and the use of lessons learned from Human Computer Interaction (HCI) and public understanding of science studies.

The design of user interfaces and the technical aspects of storage and retrieval of environmental information can be based on the current knowledge from the field of HCI and Usability Studies (Landauer, 1995; Preece, 1995). Too many existing PEIS do not use any recommendation from this useful study area. For the relatively new medium of the WWW there are more than enough recommendations for user-centred design and deployment (Nielsen, 1999). It is also important to integrate lessons from various HCI activities within GIS research (Medyckyj-Scott \& Hearnshaw, 
Forthcoming in "Computers, Environment and Urban Systems"

1993; Nyerges, Mark, Laurini \& E genhofer, 1995 Traynor \& Williams, 1997). However, while usability studies may prove helpful in the technical nuts and bolts of PEIS design, the content might still be problematic to the occasional consumer. Here, the knowledge in Public Understanding of Science (PUS) research can help. The research into PUS provide examples and lessons about the appropriate way to provide scientific information to the wider public (CO PUS, 1995; Eden, 1996; G regory \& Miller, 1998; Irwin, 1995)5. PUS knowledge might also prove useful in understanding issues like risk evaluation by the public, trust, proper feedback mechanisms and more.

Another area of study that can inform PEIS design and deployment is research into collaborative spatial decision support systems (Harris, 1995; Horita, 2000; Shiffer, 1992) and the related research

into technical aspects of PPG IS (Carver, Evans, Kingston \& Turton, 1998; Kingston, Carver, Evans \& Turton, 2000; Laurini, 2001; Shiffer, 1999). Special attention should be given to projects that utilise PPG IS within diverse audiences and user communities (such as Al-Kodmany, 1999; Harris \& Weiner, 1996; Obermeyer, 1998; Sieber, 1998). These projects and the lessons learnt through them can be merged with PUS and HCI studies, and can lead into better, more useful and accessible information systems.

\section{Conclusions}

This paper focuses on the problem-side of PEIS more than on the solution-side, as it is felt that this issue should receive attention from the research community. As such, it has just uncovered the tip of the iceberg; the issues of environmental information provision and access deserve more attention by

5 O ne of the rare examples for PUS and environmental GIS is Hoppen \& al. (1996) 
Forthcoming in "Computers, Environment and Urban Systems"

researchers. Access to information held by non-governmental entities (and especially commercial ones), the wider use of ICT by environmental groups and the way they create and use information (see for example Pickerill, 2000) or the way in which various countries implement access to information - all are issues that deserve much closer scrutiny. Finally, and as an overarching theme, we need to gain a much better understanding of how information is used within environmental decision making processes and its impact on this process. D enisev and Christoffersen (2001) provide a good starting point for such discussion.

The characteristics and problems of PEIS, as described in this paper, must be understood by GIS practitioners because they force a certain degree of reflexivity during the process of building and using of environmental models and the creation of environmental information. The reason for this is that GIS, models, and the subsequent information that is generated through them all fall under the definition of "environmental information". Thus, they have the potential to be exposed to a more informal and a less knowledgeable audience. Therefore, researchers and professionals have another obligation - on top of scientific and academic ones - which is moral and social. This obligation is to provide result in a form that is adequate for use by general users and can vividly portray issues of uncertainty and accuracy. This is by no means an easy task, but the current legislative developments leave no other option.

\section{Acknowledgement}

The author would like to express his gratitude to P.Torrens for careful review of the manuscript and to the three anonymous reviewers who helped in improving this paper.

An earlier version of this manuscript was presented in the 4th International Conference on Integrating GIS and Environmental Modeling (GIS/ EM4): Problems, Prospects and Research Needs. Banff, Alberta, Canada, September 2 - 8, 2000. 
Forthcoming in "Computers, Environment and Urban Systems"

\section{References}

Al-Kodmany, K. (1999) Using visualization techniques for enhancing public participation in planning and design: process, implementation, and evaluation, Landscapeand Urban Planning 45(1), pp. 37-45.

Aurigi, A., Batty, S., Bloomfield, D., Boott, R., Clark, J., Haklay, M., Harrison, C., Heppell, K., Moreley, J. and Thornton, C. (1999), UCL Brownfidd Reserch Nework, University College London, London, UK, 42 pp.

Avouris, N. M. and Page, B. (1995) Enirometal Informatics Methoddogy and Applications of Environmental Information Processing Kluwer Academic, D ordrecht.

Benedick, R. E. (1991) OzoneDiplamag: NewDiretions in SafegrardingthePlant, Harvard University Press, Cambridge, Mass.

Blowers, A. (1997) Environmental Policy: Ecological Modernisation or the Risk Society?, Unban Studes, 34(5-6), pp. 845-871.

Briggs, D. (1986) Environmental Problems and Policies in the European Community, In Enmiranmental Pdiaies: an Intemational Review(Ed. Park, C. C.), Croom Helm, Beckenham, Kent, pp. 105-144.

Carson, R. (1962) Silent Sping Houghton Mifflin, Boston.

Carver, S., Evans, A., Kingston, R. and Turton, I. (1998), Geogaphical Infomation Systens on theWohld WideWea ImproingPublicPartiapationin Eniromental Deision Making Available World Wide Web, URL: http:/ / www.ccg.leeds.ac.uk/ vdmisp/ publications/ easst.html (Accessed 11th $\mathrm{Dec}$ 1998)

Chrisman, N. R. (1994) Metadata Required to D etermine the Fitness of Spatial Data for use in Environmental Analysis, In Enironmental information managenent andanalysis ecosstemtogdbal scales(Eds. Michener, W. K., Brunt, J. W. and Stafford, S. G.), Taylor \& Francis, London, pp. 177-190.

CO PUS (1995), ToKnowSäeneis toLoveit? Observations on Pudic Undastanding of SäeneRescerch Committee on the Public Understanding of Science of the Royal Society, British Association for the Advancement of Science and the Royal Institution, London, $30 \mathrm{pp}$.

D enisov, N. and Christoffersen, L. (2001), Impad of enironmental information on Deision-makingproesses and theenironment, UNEP/ GRID , Arendal, Norway, 52 pp.

D ensham, P. J. (1991) Spatial D ecision Support Systems, In Geogaphical Infomation Systems Priniples AndApplications (Eds. Maguire, D. J., G oodchild, M. F. and Rhind, D .), Longman Scientific and Technical, Harlow, England, pp. 403-412.

Eden, s. (1996) Public Participation in environmental Policy: considering Scientific, CounterScientific and Non-Scientific Contributions, PublicUndestanding of Säene, 5, pp. 183-204.

Fedra, K. (1993) G IS and Environmental Modeling, In Enwronmental Moddingwith GIS(Eds. G oodchild, M. F., Parks, B. O . and Steyaert, L. T.), Oxford University Press, New York, pp. 35-50. 
Forthcoming in "Computers, Environment and Urban Systems"

Goodchild, M. F., Parks, B. O and Steyaert, L. T. (Eds.) (1993) Environmental Moddingwith GIS, Oxford University Press, New York.

Goodchild, M. F., Steyaert, L. T., Parks, B. O ., Johnston, C., Maidment, D ., Crane, M. and G lendinning, S. (Eds.) (1996) GIS and Environmettal Mooding Progessand Restch Issues, G IS World Books, Fort Collins, CO.

Gregory, J. and Miller, S. (1998) saiemein public Plenum Press, New York.

Gunter, O . (1998) Enironmental Infomation Systems, Springer, Berlin.

Hajer, M. A. (1995) ThePditics of Enviramental Discarse, Clarendon Press, O xford.

Haklay, M. (2000), London Envirament Online-User Requirement Study- Final Repat, Centre for Advanced Spatial Analysis, UCL, London, 40 pp.

Haklay, M. (2001) Public Environmental Information Systems: Challenges and Perspectives, $\mathrm{PhD}$ thesis, D epartment of G eography, University of London, London, pp. 292.

Harris, B. (1995), Complexityin CollaborativeSpatial Deision-Making Available World Wide Web, URL: http:/ / www.ncgia.ucsb.edu/ research/ i17/ htmlpapers/ harris/ Harris.html (Accessed 22nd Dec 1997)

Harris, T. M. and Weiner, D . (1996), GIS and Socidy: TheSocial Implications of HowPeeple Spaceand Enviramet areReresetedinGIS, National Center for G eographic Information and Analysis, Santa Barbara, CA.

Healey, P. (1997) Collaborativeplanning shapingplaces in fragmeteel soieties, UBC Press, Vancouver.

Hoppen, S., Clarke, K. C., Gaydos, L. J. and A cevedo, W. (1996) Communicating Scientific Findings to the $\mathrm{G}$ eneral Public In Third Intemational Confeetred Wokkshop on IntegratingGIS and EnMronmental ModdingSanta Fe, New Mexico, USA, January 21-25, 1996,1996 (CD-RO M).

Horita, M. (2000) Mapping policy discourse with CRANES: spatial understanding support systems as a medium for community conflict resolution, Enmirament andPlanningB: Planningand Design, 27(6), pp. 801 - 814.

Irwin, A. (1995) Citizensiene a sudy of peeple expetiseand sustaimabledudqument, Routledge, London.

João, E. (1998) Use of G eographic Information Systems in Impact Assessment, In Enirarmental Methoos Reiew RetodingImpad Assessmet for theNewCentury(Eds. Porter, A. and Fittipaldi, J.), Army Environmental Policy Institute, G eorgia Institute of Technology, Atlanta, USA.

João, E. and Fonseca, A . (1996), Current Useof Geogaphical Information Systens for Enironmental Assessment: a DisassionDoument, D epartment of G eography, London School of Economics, London.

Kingston, R., Carver, S., Evans, A. and Turton, I. (2000) Web-based public participation geographical information systems: An aid to local environmental decision-making, Computes, Enironment and Urban Systems, 24(2), pp. 109-125.

Landauer, T. K. (1995) TheTradlewithComputess Usfilness, Usability, and Produdivity, MIT Press, Cambridge, Mass.

Latour, B. (1993) WeHaveNere Been Modem, Harvard University Press, Cambridge, Mass.

Laurini, R. (2001) Infomationsystens for urban planing: a hypemedia coperativeapproad, Taylor \& Francis, London. 
Forthcoming in "Computers, Environment and Urban Systems"

Liverman, D. M. (1999) G eography and the G lobal Environment, Armals of theAssoiation of Ammican Geogaphes, 89(1), pp. 107-120.

Longley, P., G oodchild Michael, F., Maguire, D. J. and Rhind, D . (1999) Geogaphical Infomation Systems Priniples, Tehniques Management andApplications, John Wiley \& Sons Inc., New Y ork.

Lowenthal, D . (1990) Awareness of Human Impacts: Changing Attitudes and Emphases, In The Earth as tranformed by human action: gdbal and regional dhanges in thebiosphereouer thepast 300 years (Ed. Turner, B. L.), Cambridge University Press with Clark University, Cambridge ; New York, pp. 121-135.

Lowndes, V., Pratchett, L. and Stoker, G. (2001a) Trends In Public Participation: Part 1 - Local G overnment Perspectives, PublicAdministration 79(1), pp. 205-222.

Lowndes, V., Pratchett, L. and Stoker, G . (2001b) Trends in Public Participation: Part 2 - Citizens' Perspectives, PublicAdministration, 79(2), pp. 445-455.

MacE achren, A. M. (1995) HowMapsWork: Representation Visualization, andDesign, Guilford Press, New York.

Maguire, D. J., G oodchild, M. F. and Rhind, D . (1991) Geogaphical Information Systems Primiples and Applications Longman Scientific and Technical, Harlow, England.

McCormick, J. (1995) TheGldbal Enмirament Movenent, John Wiley \& Sons, Chichester.

Medyckyj-Scott, D . and Hearnshaw, H. M. (1993) Human fadarsin geogaphical information systers, Belhaven, London.

Mowrey, M. and Redmond, T. (1993) Notin Our Badkyard thePeepleandEvents that Shapeel Amrica's Modem Eniranmental Movenet, W. Morrow, New Y ork.

Nielsen, J. (1999) DesigingWdbUsablity: ThePradieof Simpliaty, New Riders Publishing, New Y ork.

Nyerges, T. L., Mark, D. M., Laurini, R. and Egenhofer, M. J. (Eds.) (1995) CognitiveAspeets of Human-Computer Interadion for GeographicInfomation Systems, Kluwer A cademic Publishers, D ordrecht, The Netherlands.

O bermeyer, N. J. (1998) The Evolution of Public Participation G IS, Cartogaphy andGeogaphic Infomation Systems, 25(2), pp. 65-66.

O ECD (2000), OECD Seminar - PublicA cess toEnirometal Information Proceedings, Organisation for Economic Co-operation and D evelopment, Athens, $246 \mathrm{pp}$.

Pickerill, J. (2000) Spreading the green word? Using the Internet for environmental campaigning, Ecos, 21(1), pp. 14-24.

Pipes, S. and Maguire, F. (1997) Behind the Green D oor In MappingA wareness Vol. 11, pp. 28-29.

Porritt, J. (2000) PlayingSafe Saieneand theEniranment, Thames \& Hudson, London.

Preece, J. (1995) Human-compter Interadion, Addison-Wesley Pub. Co, Wokingham, England.

Princeton Economic Research Inc. (1998), Enviromettal Data and Infomation InteimFindings from the EPA Customer Survey(PhaseIII Repat), Washington D C, 112 pp.

Raskin, J. (2000) TheHumaneInteface, Addison Wesley Longman, Inc., Reading, Massachusetts.

Shiffer, M. J. (1992) Towards a Collaborative Planning System, Enмronment and PlaningB: Planing andDesign, 19, pp. 709-722. 
Shiffer, M. J. (1999) Managing Public Discourse: towards the augmentation of GIS with Multimedia, In Geogaphical Information Systens(Eds. Longley, P., G oodchild Michael, F., Maguire, D. J. and Rhind, D.), John Wiley \& Sons Inc., New York, pp. 723-732.

Sieber, R. E. (1998) G eographic Information Systems in the Environmental Movement In Empowement, Marginalization and PudicPartiapetion GIS Santa Barbara, CA,14-17th Oct.,1998.

Sieber, R. E. (2000) Conforming (to) the opposition: The social construction of geographical information systems in social movements, Intemational Jaumal of Geogaphical Infomation Saience, 14(8), pp. 775-793.

Traynor, C. and Marian, G. W. (1995) Why Are Geographic Information Systems Hard To Use? In Computer Human InteradionACM, D enver, C0 ,7-11 May,1995, pp. 288-289.

Traynor, C. and Williams, M. G. (1997) A Study of End-User Programming for G eographic Information Systems In seventh workshoponEmpirical sudies of progammes,1997, pp. 140-156.

U.S. Congress (1970) National Environmental Policy Act, pp. P.L. 91-190, S. 1075.

UN (1972), United Nations Confeereen theHuman Enviranment- Adion Plan for theHuman Enironment, United Nations, Stockholm.

UN (1992a), Agenda 21, United Nations, Rio de Janeiro.

UN (1992b), TheRioDedaration on Enmironment and Dedqpment, United Nations, Rio de Janeiro.

UN/ ECE (1998), Convention on A cesstoInformation, PudicPatidipationin Deeisin-Makingand Access to Justicein Enironmental Mattes ECE Commitee on Environmental Policy, Aarhus, 28 pp.

UNEP (1979), Annal Reiew1978, United Nations. Environment Programme, Nairobi.

USD O C/ NTIA (1995), FallingThrangh TheNe: A Survey of the"HaveNds" in Rural and Unban Amrica, NTIA, Washington D.C.

USD O C/ NTIA (1998), FallingThraghTheNe II: NewData on theDigital Divide, NTIA, Washington D.C.

USD O C/ NTIA (1999), Falling Thrang TheNe : DefiningtheDigtal Divide, NTIA, Washington D .C.

Wallen, C. C. (1997), Histay of "Earthuatch" 1972-1995, A vailable World Wide Web, URL: http:/ / www.unep.ch/ earthw/ History.htm (Accessed 31st O ct 1998)

WCED and Brundtland, G. H. (1987) Our CommonFuture, Oxford University Press, Oxford.

Wilson, D. (1999) Exploring the limits of public participation in local government, Parliamentary Affairs, 52(2), pp. 246-259. 